\title{
An Exploration and Practice on Improvement of Thesis Quality for Postgraduates in Provincial Agricultural Universities
}

\author{
Yanhui $\mathrm{CHEN}^{1, \text { a }}$ \\ ${ }^{1}$ Graduate School of Jilin Agricultural University, 130118, Changchun, China \\ aemail:yanhuichenc@126.com
}

Keywords: Postgraduate; Thesis; Quality

\begin{abstract}
Dissertation designing is the last and important link for university teaching. How to improve the quality of undergraduates' dissertations is not only a problem that many instructors are making great effort to resolve but also an important content of enhancing the quality of higher education. This paper gives an analysis of the existing problems in postgraduate theses and corresponding causes and provides approaches to improve quality of postgraduate theses.
\end{abstract}

\section{Introduction}

Since the large-scale enrollment expansion of universities in 1999, postgraduate enrollment scale has been increased by more than $30 \%$ year by year. Under the circumstance where enrollment scale is continuously expanding, it becomes a particularly important problem to guarantee postgraduates education quality. Especially, for universities and colleges undertaking local social, economic and cultural development, due to many factors such as history of postgraduate courses, faculty condition, teaching resources and social reputation, enrollment increase has greater influence on education quality of postgraduates. Academic theses of postgraduates directly reflect the education quality and are regarded as important indicators for evaluating research capability, innovation ability and academic competency of the postgraduates. With the example of a certain local university, and on the basis of overall analysis of the quality of theses of postgraduates from the university, this paper aims at finding the popular existing problems in academic theses in some local universities and providing countermeasures for improving quality of theses of postgraduates from those universities.

\section{Existing Problems in Postgraduate theses}

Experiment in thesis and its preparation require certain efforts, time and expenses. Thus, if the student fails to choose a topic according to his personal situation and existing research condition and make a proper experiment design, it will not be a waste of expenses but also his time and consequently, he may not finish on time the academic thesis and even successfully graduate from the college ${ }^{[1]}$. At present, there are the following kinds of problems existing in postgraduate theses :

Inappropriate topic

The students blindly pursue for topics with "large scope, wide range and profound connotation”, In this case, they tend to choose a topic with excessively large scope and the research objective is not clear, which finally results in vagueness and generality of the thesis rather than innovation. Sometimes, they only pay attention to "novel, peculiar and unusual" topics and violate the professional principle and feasibility principle, which fail to reflect the perspectiveness and value of the research field in the academic thesis. In addition, wrong timing of the topics includes repetition of research content and lack of literature reading, for which, the thesis is no longer of research value ${ }^{[2]}$.

Lack of content innovation

On one hand, those postgraduate theses are in lack of originality, not only lack of original materials they collect themselves but also lack of scientificity and accuracy of the reference materials. On the other hand, those theses are in lack of innovation, which means, there are neither new problems found nor new ideas, thoughts and methods for solving problems. 
Low scientific and technical content

The theses are not duly scientific and some theses only provide general experiments. The students are not capable of data processing and interpretation and fail to make correct interpretations and judgments about the experiments results. Some students are not good at experimental practice, consequently their research results are in lack of sound support from necessary experiments ${ }^{[3]}$. What's more, research results are in lack of practicability for they are only centered on superficial phenomena without in-depth analysis and reflection.

Low writing proficiency

Theses are in poor logical structure and dedifferentiation among research objective, meaning, methods, results and conclusions. Besides, most theses are with ill-formed manner of writing not up to standard, inappropriate wording in Chinese and English abstract and nonstandard reference of bibliography and annotation of charts.

\section{Analysis of Factors Influencing Quality of Theses}

Innovation ability in thesis is to be improved

It is stipulated in the Temporary Measures for Implementation of Regulations of the People's Republic of China on Academic Degrees that "master thesis shall contains new ideas about the subjects under research to prove that the author is capable of scientific research or take on professional work independently and make creative achievements in science or professional technology". Thus, it can be seen that, innovation is the primary and fundamental requirement of thesis. Innovation ability is the based on the other four skills and can only be enhanced by improvement of other skills ${ }^{[4]}$.

Students' writing ability is to be improved

Lack of proper writing skills of students are mainly reflected by ill-formed charts, non-standard bibliography and wrongly written or mispronounced characters, incompletely unified units of measurement. On one hand, those errors are resulted from carelessness ,undisciplined academic attitude; and on the other hand, students are not sure about the involving standards and even barely know them.

Unsound basic theory and professional knowledge

The quality of thesis is firstly dependent on extent of mastery of basic theory and professional knowledge of the author ${ }^{[5]}$. The author cannot write qualified thesis without such precondition. According to results of the double-blind review, the problems described under this item accounts for $20 \%$. Thus, it can be seen that there is still a gap between breadth of basic theory and deepness of professional knowledge.

The ability to analyze and summarize literature is to be enhanced

Under the item of literature review, due to the timeworn literature lack of bibliographic retrieval and limitations on English proficiency, few postgraduates fail to consult foreign literature and consequently they know a little about the research status of their topic and fail to keep up with the latest research trends in their field of research. It is shown that, access to literature of students and ability to analyze and summarize literature is to be enhanced.

Poor attention paid to academic value of topic selection

Appropriate topic is directly related to quality of the thesis. However, some students are not given the chance to choose a topic but to accept the one assigned by their tutors. Most of the tutors focus on general research and consequently students are reduced to procedural operations but independent creation ${ }^{[6]}$. Such general way of selecting topics takes into no consideration of the academic value of the topic, which is mainly reflected in two aspects, namely topic of little theoretical significance and practical value and obsolete topics.

\section{Measures for Improvement of Quality of Postgraduate Thesis}

To strengthen science-related moral education to curb fickleness

On one hand, it is necessary to strengthen education of academic morality by positive example 
and adopt practicable measures to do a good job of learning atmosphere and science-related moral education form various perspectives, such as education laws, regulations and self-discipline. At the same time, favorable education environment shall be formed for science-related morality; on the other hand, strict regulations on punishment shall be established to reinforce inspection and supervision of thesis and safeguard academic dignity. Any bad behavior shall be seriously investigated and corrected.

To deepen teaching reform and intensify training of students in professional knowledge and innovation ability so as to lay a solid foundation for proper writing of thesis.

Basic qualities and abilities of postgraduates in finishing high-quality innovative thesis include solid theoretical foundation, systematical professional knowledge, originality in finding new problems, scientific ways of thinking, methods to analyze and study problems, ability to consult and process document literature and writing ability, and it is course teaching that is the vital link in cultivating those abilities of postgraduates ${ }^{[7]}$. As such, it is the important premise and guarantee for improving quality of postgraduate thesis to deepen course teaching reform and improve teaching quality.

To intensify thesis guidance and establish strict thesis proposal system

Tutors shall intensify guidance on topic selection of thesis and cooperate with the teaching and research office in order to strengthen consciousness of responsibility of tutors and enable the tutor group and the teaching and research office to play the positive role. Strict thesis proposal system shall be established under supervision of review panel mainly membered by the tutor group, who are responsible for defense, review and evaluation of rationality, scientific nature, innovation and feasibility of the thesis topic, topic content, research program and research approach and give detailed suggestions on correction to the students ${ }^{[8]}$.

To reinforce evaluation of postgraduate tutors who are prepared for both promotion and demotion

First of all, for evaluation of postgraduate tutors, the concept of tutor being the first person responsible for students shall be strengthened so as to urge the tutors to be more responsible for students. Secondly, evaluation of tutors shall be conducted throughout the entire process of postgraduate cultivation, including thesis proposal, mid-term evaluation, thesis and defense and other links. The postgraduate management department of the school shall play its proper role and carry out inspection and evaluation of tutor's guidance on a regular basis.

To introduce social teaching resources so as to integrate improvement of thesis quality and implementation of student employment

The leadership of the school shall actively utilize social teaching resources and proactively launch joint teaching with organizations having recruitment program outside the school thus to assign the graduates specifically to relevant organizations outside the school to finish graduation thesis during employment practice in the two ways of "part-time" and "full-time" practice. By thus doing, the students could be more active in writing high-quality thesis of more realistic pertinence and practical applicability. Besides, it can promote the virtuous cycle of thesis design driving employment practice and in return, the practice helping students in finishing high-quality thesis. In addition, quality of undergraduate paper is improved as well ${ }^{[9]}$.

\section{Conclusions}

Thesis gives direct reflection of the quality of postgraduate cultivation and the basic guarantee for sustainable development of postgraduate education. On this account, it is a long-term project to improve quality of thesis. As long as we pay adequate attention to all links in postgraduate cultivation process and mobilize initiative of students, tutors and management departments with a rigorous attitude, can we successfully achieve the goal of improving thesis quality and provide more qualified for our nation. 


\section{References}

[1] Gu Yuehua. Practical Exploration on Strengthening Quality Control of Postgraduate Thesis [J]. China Electric Power Education, 2008, 123(10): 46 47.

[2] Wang Chunxia. Exploration and Practice on Educational Quality Assurance System for Postgraduates in Agricultural Universities [ J]. China Agricultural Education,2008(6): 37 39.

[3] Chen Zhongsheng. Strengthen Scientific Management Process to Improve Quality of Postgraduate Tthesis[J]. Journal of Higher Education Research, 2008, 31(3): 37 39.

[4] Lv Juanfei. A Brief Discussion on Quality Guarantee System of Two-year Postgraduates Cultivation [J]. Higher Agricultural Education, 2008(3): 70 72.

[5] Jin Yunxue. A Brief Discussion Current Situation Analysis and Countermeasure [J]. China Education Innovation Herald, 2008(20): 25 26.

[6] Gao Kunhua. Exploration and Practice on Reform of Thesis Evaluation and Defense [J] . Academic Degrees \& Graduate Education, 2007 (2).

[7] Zhao Hongwei. Approaches to Improve Quality of Postgraduate Thesis [J]. Journal of Northeast Agricultural University(Social Science Edition),2010,(2):17-20.

[8] Song Ming. Optimization Strategies for Optimization of Quality of Postgraduate Thesis From the Perspective of Overall Quality Concept [J]. Journal of Educational Science of Hunan Normal University ,2012,(1):72-75.

[9] Huang Yihong. Analysis and Countermeasures Study for Problems in Quality of Postgraduate Thesis [J]. Journal of Zhangzhou Institute of Technology ,2011,(9):75-78. 